\title{
MORPHOLOGICAL HETEROGENEITY OF HeLa CELL MITOCHONDRIA VISUALIZED BY A MODIFIED DIAMINOBENZIDINE STAINING TECHNIQUE
}

\author{
J. W. POSAKONY*, J. M. ENGLAND* AND G. ATTARDI† \\ Division of Biology, California Institute of Technology, Pasadena, \\ California 91125 , U.S.A.
}

\section{S U M M A R Y}

The diaminobenzidine (DAB) technique for the ultrastructural localization of sites of cytochrome $c$ oxidase activity in animal tissues has been adapted to the visualization of mitochondria in animal cells growing in culture.

The modified technique allows the staining of mitochondria in all cells in coverslip preparations for light microscopy. Electron microscopy of thin sections of material treated by this method has revealed that all mitochondrial profiles within a cell (and only these) are stained, and they exhibit a well preserved size and internal structure.

Coverslip cultures of synchronized and unsynchronized HeLa (F-3 I 5$)$ cells stained with the DAB reaction were examined under oil immersion. In the majority of the cells, mitochondria were recognized as discrete bodies in the thinner peripheral portion of the cytoplasm. This observation indicates that in a large proportion of HeLa F-3 I 5 cells, at least under the growth conditions used here, the mitochondrial complement is divided into distinct organelles. This examination also revealed a considerable morphological heterogeneity of mitochondria, which exhibited an ovoid or short rod-like or, less frequently, long filamentous shape, with some evidence of branching. The variability in mitochondrial morphology appeared to be far more pronounced between different cells than within individual cells; this cellular heterogeneity was not related in any obvious way to cell-cycle-dependent changes.

\section{INTRODUCTION}

The question of the morphology and individuality of mitochondria in eukaryotic cells has attracted considerable attention in recent years. Two general experimental approaches have proven useful in the investigation of this problem: ( 1 ) light microscopy using phase contrast and/or certain cytological stains, and (2) electron microscopy of serial thin sections of fixed cells. There are, however, limitations to these methods. The first suffers from the difficulties of non-specificity of the stains and uncertainty of identification of the organelles; the second, though probably much more reliable, allows the examination of only a relatively small number of cells at a time, due to the time-consuming task of 3 -dimensional reconstruction.

It seemed that these difficulties could be overcome satisfactorily for many purposes

- Mr Posakony's present address is the Department of Biology, University of California, San Diego, La Jolla, California 92037, U.S.A. Dr England's present address is The Wistar Institute, Philadelphia, Pennsylvania 19104, U.S.A.

+ To whom reprint requests should be addressed. 
by employing a cytochemical marker which was both specific for mitochondria and suitable for use with intact cells at the light-microscope level. Several years ago, Seligman, Karnovsky, Wasserkrug \& Hanker (ig68) reported the use of 3-3'diaminobenzidine $(\mathrm{DAB})$ for the ultrastructural demonstration of sites of cytochrome $c$ oxidase activity in animal tissues. Their study (Seligman et al. 1968) indicated that, under the conditions utilized, this reagent gives a precise localization of enzymic activity along the inner mitochondrial membrane and that the intracellular reaction is specific for mitochondria. These features made the DAB stain an obvious choice as a marker for the study of mitochondrial morphology. However, our attempts at applying the method described by Seligman et al. (1968) to human cells in tissue culture gave unsatisfactory results at both the light- and electron-microscope levels. A modified technique is herein described which allows the direct visualization with light microscopy of the entire mitochondrial complement in cells grown on coverslips. This paper further reports the results of a careful examination of the morphology and physical interrelationship of mitochondria in synchronized and unsynchronized HeLa cell cultures stained according to this technique.

\section{MATERIALS AND METHODS}

\section{Cell culture}

HeLa cells (strain F-3 I5) were grown in monolayer cultures at $37^{\circ} \mathrm{C}$ in modified Eagle's medium (Dulbecco \& Freeman, 1959) plus ro \% calf serum.

\section{Conditions of fuxation and staining}

In the initial staining experiments, the following conditions of fixation and DAB incubation described by Seligman et al. (1968), were employed. Cells were fixed for 15 min at $4{ }^{\circ} \mathrm{C}$ with $4 \%$ freshly prepared formaldehyde in $0.05 \mathrm{M}$ sodium phosphate buffer ( $\mathrm{pH} \mathrm{7.4}$ ) containing $0.15 \mathrm{M}$ sucrose, and washed several times with $0^{\circ} \mathrm{I} \mathrm{M}$ phosphate buffer plus O.I5 M sucrose. They were then incubated for $\mathrm{I} h$ at $37^{\circ} \mathrm{C}$ in $0.05 \mathrm{M}$ Tris buffer $\left(\mathrm{pH} 7.4\right.$ at $25^{\circ} \mathrm{C}$ ) containing 3-3' diaminobenzidine tetrahydrochloride (Sigma Chemical Company, St Louis, Missouri) $(0.5 \mathrm{mg} / \mathrm{ml})$, washed with $0.05 \mathrm{M}$ Tris buffer, and treated for $\mathrm{I} h$ at room temperature with $\mathrm{I} \%$ osmium tetroxide $\left(\mathrm{OsO}_{4}\right)$ in $0_{1} \cdot 1 \mathrm{M}$ collidine buffer $(\mathrm{pH} 7 \cdot 2)$.

Due to the poor results obtained using this procedure, an attempt was made to adapt its use to HeLa cells in culture, in the course of which several different modifications of the above conditions were tested; these are described briefly in the Results section. The fully modified technique employed for the studies reported here is as follows:

Cells were washed with warm Eagle's medium and fixed for 10 min at $4{ }^{\circ} \mathrm{C}$ with $3 \%$ freshly prepared formaldehyde, $0.1 \% \mathrm{CaCl}_{2}, 0.44 \mathrm{M}$ sucrose in $0.05 \mathrm{M}$ sodium cacodylate buffer at $\mathrm{pH} 7.4$. They were then washed thoroughly 3 times with $0.44 \mathrm{M}$ sucrose, $2 \times 10^{-5} \mathrm{M}$ EDTA in $0.05 \mathrm{M}$ cacodylate buffer $(\mathrm{pH} 7.4)$ at $4{ }^{\circ} \mathrm{C}$, and exposed for $3 \mathrm{~h}$ at $37^{\circ} \mathrm{C}$ to the DAB incubation medium: this consisted of DAB $(0.5 \mathrm{mg} / \mathrm{ml}), 0.44 \mathrm{M}$ sucrose, $2 \times 10^{-6} \mathrm{M}$ EDTA in $0.05 \mathrm{M}$ Tris buffer $\left(\mathrm{pH}_{7} \cdot 4\right)$. The cells were then washed twice at room temperature with $0.44 \mathrm{M}$ sucrose in $0.05 \mathrm{M}$ Tris buffer ( $\mathrm{pH} 7.4$ ), treated for $\mathrm{I} \mathrm{h}$ with $\mathrm{I} \%$ osmium tetroxide in $0 . \mathrm{I} \mathrm{M}$ collidine buffer $(\mathrm{pH} 7 \cdot 2$ ), and prepared for either light or electron microscopy.

The staining reaction was monitored for mitochondrial specificity (Seligman et al. 1968) by testing its sensitivity to low $\left(\mathrm{IO}^{-3}-1 \mathrm{O}^{-5} \mathrm{M}\right.$ ) concentrations of $\mathrm{KCN}$.

\section{Preparation for microscopy}

For light microscopy, stained coverslip cultures were dehydrated in a graded series of ethanols, cleared with xylene, and mounted on glass microscope slides. The slides were 
examined with phase-contrast optics using a Zeiss Photomicroscope II; detailed study required (a $\times 100$ oil immersion objective. For electron microscopy, cells were removed by trypsinization from $100-\mathrm{mm}$ plastic dishes, stained as previously described, dehydrated in a graded series of ethanols, washed in propylene oxide, and embedded in Epon 812: the various treatments of the cells were carried out in suspension with intervening centrifugation steps. (Alternatively, the cells were fixed and stained with DAB while still attached to the plastic substrate, and then removed by scraping with a rubber policeman, the subsequent steps being performed as above. The original shape of the cells in culture remained fairly well preserved by this procedure.) Gold to silver thin sections of the Epon-embedded cells were lightly stained with lead citrate Venable \& Coggeshall, 1965) and examined in a Philips EM20 I electron microscope.

\section{Cell synchrony}

A synchronous population of HeLa F-3 5 cells was obtained from roller bottle cultures by the method of selective detachment of mitotic cells (Robbins \& Marcus, 1964; Terasima \& Tolmach, 1963). The harvested population had an initial mitotic index of about $87 \%$. Aliquots $\left(2 \times 10^{4}\right.$ cells $)$ were plated on coverslips and incubated at $37^{\circ} \mathrm{C}$. At various times during the cell cycle $(3,8,14,21,24$ and $27 \mathrm{~h}$ after plating), duplicate cultures were fixed, stained with DAB, and prepared for light microscopy as described above.

The temporal pattern of nuclear DNA synthesis during the cell cycle was followed by counting the percentage of labelled nuclei in light-microscope autoradiographs of parallel coverslip cultures, which had been exposed at various times in the cell cycle to $\left[M e-{ }^{3} \mathrm{H}\right]$ thymidine $(49.2 \mathrm{mCi} / \mu \mathrm{mol} ; 10 \mu \mathrm{Ci} / \mathrm{ml})$ for $30 \mathrm{~min}$ at $37^{\circ} \mathrm{C}$, rinsed with isotonic $\mathrm{NaCl} / \mathrm{KCl} / \mathrm{MgCl}_{2}$ solution, and fixed in acetic acid/ethanol $(1: 3)$. The timing of the next peak of mitotic activity was determined by counting the percent mitotic cells in parallel coverslip cultures stained at various times in the cycle with $1 \%$ acetic orcein.

\section{RESULTS}

\section{Modification of the diaminobenzidine staining procedure}

As mentioned above, direct application of the original procedure of Seligman et al. ( 1968 ) to HeLa F-3 5 cells gave unsatisfactory results. In the light microscope, most cells in coverslip cultures appeared to be unstained. A small proportion of the cells, which tended to be clustered, showed staining of variable intensity which was generally localized at the periphery of rounded intracellular bodies, but was occasionally diffused throughout the cytoplasm. In addition, a large amount of dark precipitate was frequently observed in the microscope field (Fig. I). Electron-microscopic examination of cells treated with DAB confirmed the lack of uniformity of the reaction among different cells, and also revealed a considerable variability in the degree of staining among the mitochondrial profiles within individual cells; furthermore, the mitochondria often appeared markedly expanded. It was thought that these problems depended on the physiological properties and physical situation of cells grown in culture, and hence were not encountered by Seligman et al. (1968), who used small blocks of animal tissue. A systematic investigation of the possible variables involved was undertaken in an attempt to adapt the use of DAB to cultured HeLa cells.

Some of the initial experiments employed existing modifications of the original technique: these included the use of glutaraldehyde as a fixative, and an incubation medium with a higher concentration of $\operatorname{DAB}(2 \mathrm{mg} / \mathrm{ml})$ and/or lower $\mathrm{pH}(6 \cdot 0)$ (Novikoff \& Goldfischer, 1969). In other tests, various conditions of pretreatment and incubation with catalase and cytochrome $c$ (Seligman et al. 1968) and longer treatment 
with $\mathrm{OsO}_{4}$ were tried. None of these changes had a substantial effect on the difficulties described above.

Further experiments, however, yielded the following results: (I) The intensity of the staining could be increased somewhat by a lengthened period of incubation in $\mathrm{DAB}$ ( $3 \mathrm{~h}$ instead of $\mathrm{I} \mathrm{h}$ ). (2) The complete elimination of the precipitate observed in light-microscope preparations could be effected by a combination of a very thorough washing of the coverslips after fixation and the inclusion of EDTA $\left(2 \times 10^{-5} \mathrm{M}\right)$ in the postfixation rinse medium and the DAB incubation medium. Apparently, this precipitate was a consequence of $(a)$ extracellular cross-linkage of DAB by traces of formaldehyde remaining after fixation, and $(b)$ autooxidation of $\mathrm{DAB}$ catalysed by heavy metal ions in the medium (Hanker, Anderson \& Bloom, 1972). The abovementioned steps also had the effect of markedly increasing the intensity of the stain and its uniformity from cell to cell: presumably, the prevention of non-specific extracellular polymerization of $\mathrm{DAB}$ served to make the $\mathrm{DAB}$ monomers more available for intracellular reaction. (3) The apparent swelling of mitochondria (seen at both the light- and electron-microscope levels) could be overcome by increasing the concentration of sucrose to $0.44 \mathrm{M}$ in the media used in the course of the procedure.

The staining method used for the studies reported here incorporates the last described modifications (see Materials and methods). It allows the staining of all cells in coverslip preparations examined in the light microscope (Fig. 2). By electron microscopy of thin sections of material treated by this method, only mitochondrial profiles appear to be stained, and these exhibit a well preserved size and internal structure (Fig. 3). Furthermore, the staining reaction is nearly completely inhibited by $10^{-4} \mathrm{M} \mathrm{KCN}$.

\section{Light microscopy of $\mathrm{HeLa}$ F-315 cells stained with $D A B$}

Examination under oil immersion of $\mathrm{HeLa} \mathrm{F}-3{ }^{1} 5$ coverslip cultures stained according to the modified DAB technique revealed a remarkable morphological heterogeneity of mitochondria of different cells, while the shape of the organelles within individual cells was relatively uniform. The various mitochondrial shapes observed in different cells were classified, for the purpose of quantitative analysis, into 3 main categories: (I) Round or oval (approximately $0.5-1 \cdot 5 \mu \mathrm{m}$ in diameter; Fig. 4); (2) short rod-like (with a transverse diameter of $0.5-1 \cdot 0 \mu \mathrm{m}$ and a length up to $10 \mu \mathrm{m}$ ), frequently with an uneven distribution of stain (Fig. 5); (3) long and thread-like (with a transverse diameter of $0^{\circ} 5^{-1} \cdot 0 \mu \mathrm{m}$ and a length up to $30 \mu \mathrm{m}$ ), showing some evidence of branching, often non-uniformly stained (Fig. 6). Table I shows the relative frequencies of cells in a typical unsynchronized coverslip culture classified according to their predominant mitochondrial morphology. It should be emphasized that the above classification is primarily for convenience and describes what is apparently a continuum of shapes. Furthermore, an individual cell may contain a minority of stained organelles with a morphology other than that which predominates in the cell (Fig. 7). There did not appear to be any obvious clustering of cells with similar mitochondrial configurations.

With regard to the question of the physical interrelationship of mitochondria, it 
was found that a critical examination of the stained organelles was possible only in the peripheral portions of a cell, where the cytoplasm is thinner than in the region surrounding the nucleus. Particularly in cells containing mitochondria of types ( $I$ ) or (2), the bodies observed in the peripheral cytoplasm were for the most part discrete (Figs. 4, 5, 7). Discrimination of this sort was more difficult in cells containing longer rod-like or filamentous bodies, and little information could be obtained with regard to the interrelationship of the organelles in these cells. Among the individual filamentous mitochondria which could occasionally be observed there were a few which exhibited a branched structure (Fig. 6).

Table I. Relative frequencies of cells classified according to their predominant mitochondrial morphology $(\%)$

\begin{tabular}{ccc}
\hline Round or oval* & Short rod-like* & Filamentous* \\
\hline 55 & 39 & 6
\end{tabular}

A total of approximately 500 unsynchronized cells from one coverslip preparation were analysed.

- See text for details; see also Figs. 4-6.

Cell-cycle-dependent changes in mitochondrial morphology could conceivably generate, in an unsynchronized population, the intercellular heterogeneity observed here. To investigate this possibility, a synchronous population of HeLa F-315 cells was obtained by selective detachment and aliquots were plated on coverslips; at various times in the cell cycle (at 3, 8, 14, 21, 24 and 27 h), duplicate coverslip cultures were stained with $\mathrm{DAB}$ according to the modified technique. As determined from parallel samples (see Materials and methods), the peak of nuclear DNA synthesis in this population occurred at about $20 \mathrm{~h}(\mathrm{Oh}$ is considered to be the time of plating on to coverslips of the original mitotic population), while the peak of mitotic activity at the end of the cell cycle occurred at about $28 \mathrm{~h}$.

The 6 sets of duplicate coverslips which were stained with DAB were examined under oil immersion to determine if the relative frequencies of cells containing the various morphological types of mitochondria described above differed markedly at any point in the cell cycle from those observed in unsynchronized populations (Table $\mathbf{1}$ ). The cells in the $3^{-h}$ samples were neither large enough nor sufficiently flattened out on the substrate to permit a meaningful analysis. In all of the other samples, although no attempt was made at precise quantitation, cells containing the various morphological types were found in approximately the same proportions as in the unsynchronized culture.

\section{DISCUSSION}

\section{Visualization of mitochondria by $D A B$ staining}

The use of diaminobenzidine as a mitochondrial marker in morphological studies allows the analysis, in light-microscope preparations, of a large number of cells in a 
short time with a probe which is highly specific for mitochondria. Our observations demonstrate the feasibility of DAB staining for high-resolution optical microscopy of mitochondria in an in vitro animal cell line.

In the present work, both the cyanide sensitivity of the $D A B$ staining reaction and electron microscopy of DAB-treated cells have indicated the specificity of the DAB reaction for mitochondrial membranes, in agreement with the findings of Seligman et al. (1968). Moreover, a quantitative study by Storrie \& Attardi (1972), employing the modified $\mathrm{DAB}$ method described here, has provided evidence that the entire mitochondrial complement within a cell is stained by DAB. These authors determined that, in electron micrographs of thin sections of HeLa $\mathrm{S}_{3}$ cells, the number of DABpositive profiles per cell was at least as great as the number per cell of morphologically identifiable mitochondria in unstained cells. Finally, the mild fixation conditions and the optimized tonicity of the media used in the $\mathrm{DAB}$ procedure would tend to argue against any artifactual rearrangement of the mitochondrial membranes during experimental manipulation. All of the above considerations strongly suggest that the DAB stain accurately reflects the in vivo configuration of the mitochondrial membranes. The uneven distribution of DAB stain seen in some mitochondria in the lightmicroscope preparations may be indicative of a non-uniform density of cristae membranes within the organelles of intact cells.

\section{Heterogeneity in mitochondrial morphology}

The broad spectrum of mitochondrial shapes in HeLa F-3 5 cells, as revealed by DAB staining, underscores the complex and dynamic character of the structure of mitochondria. The remarkable plasticity of these organelles was made especially apparent about 20 years ago by phase-contrast microscopic examination of living cells in culture (Frederic, 1958; Frederic \& Chèvremont, 1952): branching, fusion, constriction and fragmentation of mitochondria were frequently observed and recorded by time-lapse cinematography. Our findings of such dissimilar forms as ovoids and branched filaments support the concept that functional mitochondrial membranes may exist in a wide variety of configurations in HeLa cells. Such structural diversity has also been observed in recent electron-microscopic analyses of serial thin sections of rat liver cells (Brandt, Martin, Lucas \& Vorbeck, 1974) and rat heart fibres (Berger, Bergengren \& Person, 1974), which have revealed rod-shaped, ovoid, V-shaped, diskoid, and filamentous organelles, as well as more complex branched forms.

The most striking observation made in our examination of DAB-treated HeLa cell coverslip cultures is that the variability in mitochondrial morphology is far more pronounced between different cells than within an individual cell. The reasons for this cellular heterogeneity are difficult to assess. From our observations of synchronized cells stained with $\mathrm{DAB}$, it would appear that cell-cycle-dependent changes in mitochondrial configuration are not involved. Local differences in environmental conditions on the solid substrate could conceivably play a role. 


\section{Individuality of mitochondrial organelles}

In recent years, a number of electron-microscopic studies employing the technique of serial sectioning have indicated the presence of one or very few giant, highly branched mitochondria per cell in yeast and several other lower eukaryotic organisms (Arnold, Schimmer, Schotz \& Bathelt, 1972; Burton \& Moore, 1974; Calvayrac, van Leute \& Butow, 197I ; Calvayrac \& Butow, 197I; Calvayrac, Butow \& Lefort-Tran, 1972; Grimes, Mahler \& Perlman, 1974 $a$; Hoffman \& Avers, 1973; Keddie \& Barajas, 1969; Osafune, 1973; Stevens, 1974). Hoffman \& Avers (1973) suggested that this situation might be general in eukaryotic cells. However, there is considerable evidence, particularly in yeast, that the number and degree of interconnexion of mitochondria can vary widely in relationship to the strain (Grimes et al. 1974a), to the growth or nutritional conditions (Brandt et al. 1974; Calvayrac et al. 1971 ; Calvayrac \& Butow, 1971; Grimes, Mahler \& Perlman, 1974 $b$; Stevens, 1974), and to the stage of the growth cycle (Calvayrac et al. 1972; Keddie \& Barajas, 1969; Osafune, I973).

The organization of the chondriome in mammalian cells has been examined in a few recent studies. A serial-section analysis of rat liver cells by Brandt et al. (1974) has not supported the idea of a single or a few mitochondria per cell, though some of the organelles in these cells exhibited a highly branched, tubular structure. In diploid human fibroblasts grown in vitro and examined in the light microscope after nonspecific cytological staining, Schneidl (1974) has observed long and filamentous mitochondria, which appeared to be interconnected to a considerable extent.

In the present work, mitochondria were seen as discrete bodies in the peripheral cytoplasm of a majority of the cells (particularly those with ovoid or short rod-like mitochondria). This observation indicates that, in a large proportion of HeLa F-31 5 cells, the mitochondrial complement is divided into distinct organelles under the growth conditions used here. The long, thread-like mitochondria predominant in a small percentage of the cells showed some evidence of a branched configuration, suggesting that, at least in these cells, mitochondrial fusion may occur.

The evidence presented in this paper indicates that the modified DAB staining procedure described here will be especially suitable for studies of mitochondrial organization under various growth conditions in mammalian cells grown in vitro.

The useful suggestions of Dr M. J. Karnovsky are gratefully acknowledged, as is the excellent technical assistance of Ms B. Keeley.

This work was supported by NIH grant GM-I I 726, a Dernham Fellowship (D I 96) of the American Cancer Society (J.E.), and an NSF Summer Research Traineeship (J.P.).

\section{REFERENCES}

Arnold, C. G., Schimmer, O., Schotz, F. \& Bathelt, H. (1972). Die Mitochondrien von Chlamydomonas reinhardi. Arch. Mikrobiol. 81, 50-67.

Berger, E. R., Bergengren, C. \& Person, P. (i974). On the morphological heterogeneity of rat cardiac mitochondria. 7. Cell Biol. 63, $22 a$.

Brandt, J. T., Martin, A. P., Lucas, F. V. \& Vorbeck, M. L. (1974). The structure of rat liver mitochondria: a reevaluation. Biochem. biophys. Res. Commun. 59, 1097-1 103. 
Burton, M. D. \& Moore, J. (1974). The mitochondrion of the flagellate Polytomella agilis. F. Ultrastruct. Res. 48, 414-419.

Calvayrac, R. \& Butow, R. A. (1971). Action de l'antimycine A sur la respiration et la structure des mitochondries d'Etuglena gracilis Z. Arch. Mikrobiol. 80, 62-69.

Calvayrac, R., Butow, R. A. \& Lefort-Tran, M. (1972). Cyclic replication of DNA and changes in mitochondrial morphology during the cell cycle of Euglena gracilis (Z). Expl Cell Res. 71, 422-432.

Calvayrac, R., van Leute, F. \& Butow, R. A. (i97r). Euglena gracilis: formation of giant mitochondria. Science, N.Y. 173, 252-254.

Dulbecco, R. \& Freeman, G. (1959). Plaque production by the polyoma virus. Virology 8, $396-397$.

FreDERIC, J. (1958). Recherches cytologiques sur le chondriome normal ou soumis it l'expérimentation dans de cellules vivantes cultivées in vitro. Archs Biol., Liège 69, 167-349.

Frederic, J. \& Chèvremont, M. (1952). Recherches sur les chondriosomes de cellules vivantes par la microscopie et la microcinématographie en contraste de phase. Archs Biol., Liège 63, IO9-I3I.

Grimes, G. W., Mahler, H. R. \& Perlman, P. S. (I974a). Nuclear gene dosage effects on mitochondrial mass and DNA. F. Cell Biol. 6r, 565-574.

Grimes, G. W., Mahler, H. R. \& Perlman, P. S. (1974b). Mitochondrial morphology. Science, N.Y. 185, 630-631.

Hanker, J. S., Anderson, W. A. \& Bloom, F. E. (1972). Osmiophilic polymer generation: catalysis by transition metal compounds in ultrastructural cytochemistry. Science, N.Y. 174, 99 I -993 .

Hoffman, H.-P. \& Avers, C. J. (1973). Mitochondrion of yeast: ultrastructural evidence for one giant, branched organelle per cell. Science, N.Y. 181, 749-75 I.

Keddie, F, M. \& Barajas, L. (1969). Three-dimensional reconstruction of Pityrosporum yeast cells based on serial section electron microscopy. F. Ultrastruct. Res. 29, 260-275.

NovikofF, A. B. \& Goldfischer, S. (I 969). Visualization of peroxisomes (microbodies) and mitochondria with diaminobenzidine. F. Histochem. Cytochem. 17, 675-680.

Osafune, T. (1973). Three-dimensional structures of giant mitochondria, dictyosomes, and 'concentric lamellar bodies' formed during the cell cycle of Euglena gracilis $(Z)$ in synchronous culture. F. Electron Microsc. 22, 5 1-6r.

Robbins, E. \& Marcus, P. I. (1964). Mitotically synchronized mammalian cells: a simple method for obtaining large populations. Science, N.Y. 144, I I 52-I I 53 .

SCHNEIDL, W. (1974). Veranderungen des Mitochondrienbestandes wihrend des Zellzyklus. Cytobiologie 8, 403-4II.

Seligman, A. M., Karnovsky, M. J., Wasserkrug, H. L. \& Hanker, J. S. (ig68). Nondroplet ultrastructural demonstration of cytochrome oxidase activity with a polymerizing osmiophilic reagent, diaminobenzidine (DAB). F. Cell Biol. 38, 1-r 4 .

StEveNs, B. J. (1974). Variation in mitochondrial numbers and volume in yeast according to growth conditions. 7. Cell Biol. 63, 336a.

Storrie, B. \& AtTard, G. (1 972). Mode of mitochondrial formation in HeLa cells. F. Cell Biol. 56, $833 \sim 838$.

Terasima, T. \& Tolmach, L. J. ( 1963$)$. Growth and nucleic acid synthesis in synchronously dividing populations of HeLa cells. Expl Cell Res. 30, 344-362.

Venable, J. H. \& Coggeshall, R. ( 1965$)$. A simplified lead citrate stain for use in electron microscopy. F. Cell Biol. 25, 407-408.

(Received 28 April 1975) 


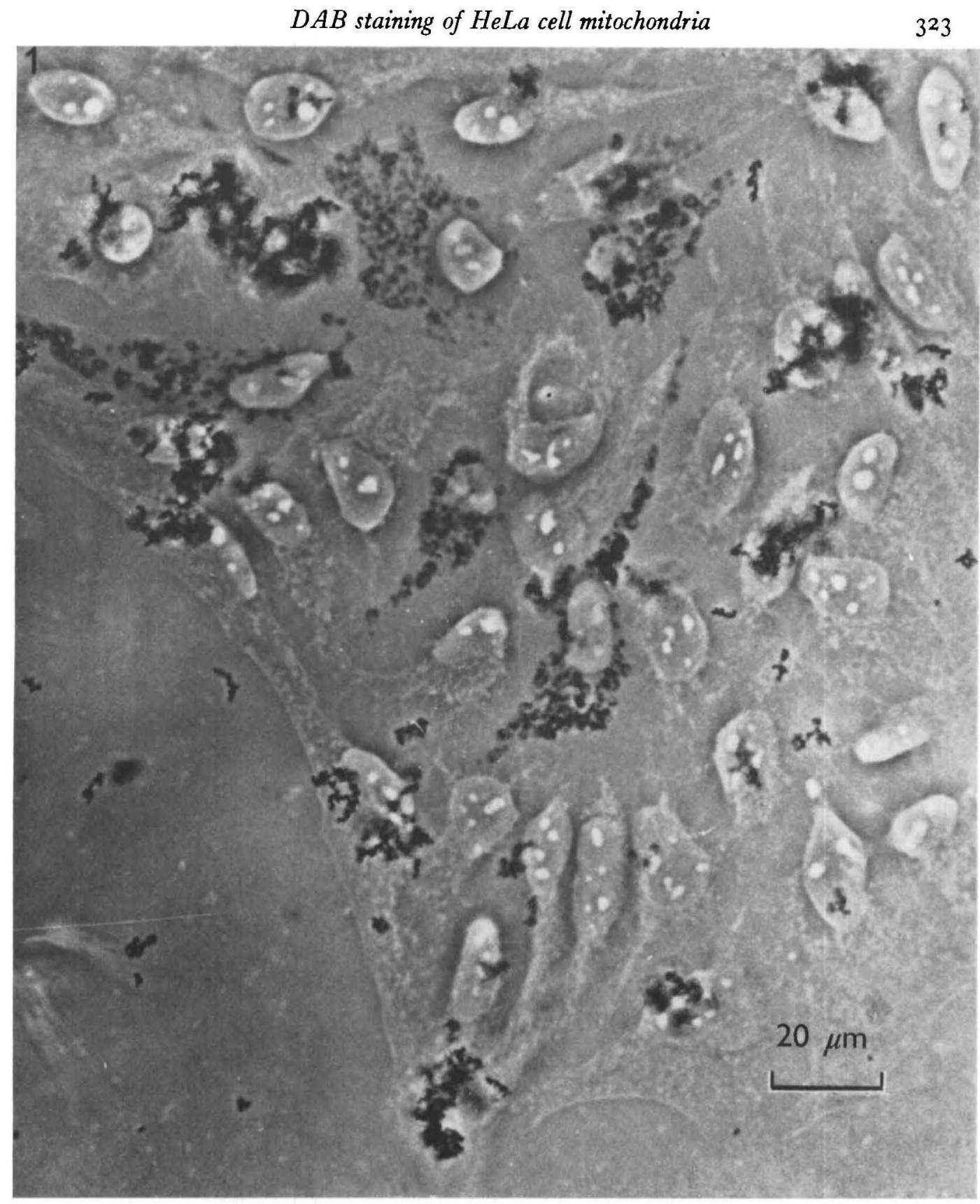

Fig. I. Portion of a HeLa F-3 I 5 cell coverslip culture stained with DAB according to the method described by Seligman et al. (1968) (see Materials and methods). The DAB stain appears in a minority of the cells, localized at the periphery of round intracellular bodies. Note also the presence of a precipitate scattered throughout the field. Phasecontrast, $\times 800$. 
Fig. 2. HeLa F-3 15 cell coverslip culture stained with the modified technique given in the text. The uniformity of staining of different cells is clearly apparent. Phasecontrast, $\times 920$.

Fig. 3. Electron micrograph of a HeLa F-3 15 cell stained with DAB according to the modified method detailed in the text. The mitochondria are uniformly stained along their periphery (several also show stained cristae) and do not appear expanded, as judged from comparison with mitochondria in glutaraldehyde-fixed cells not subjected to the DAB staining reaction (not shown). $\times 16300$. 
$D A B$ staining of HeLa cell mitochondria
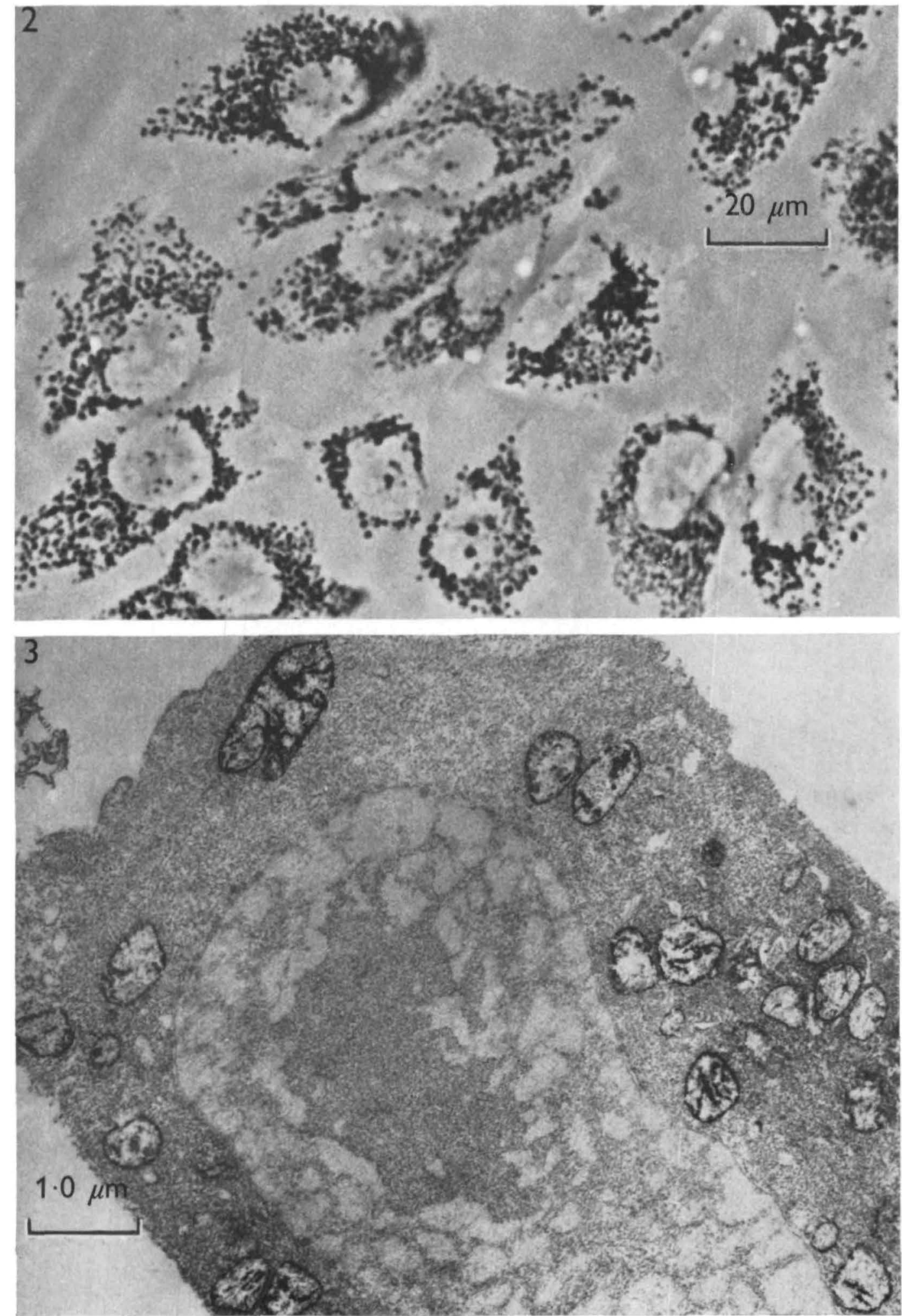


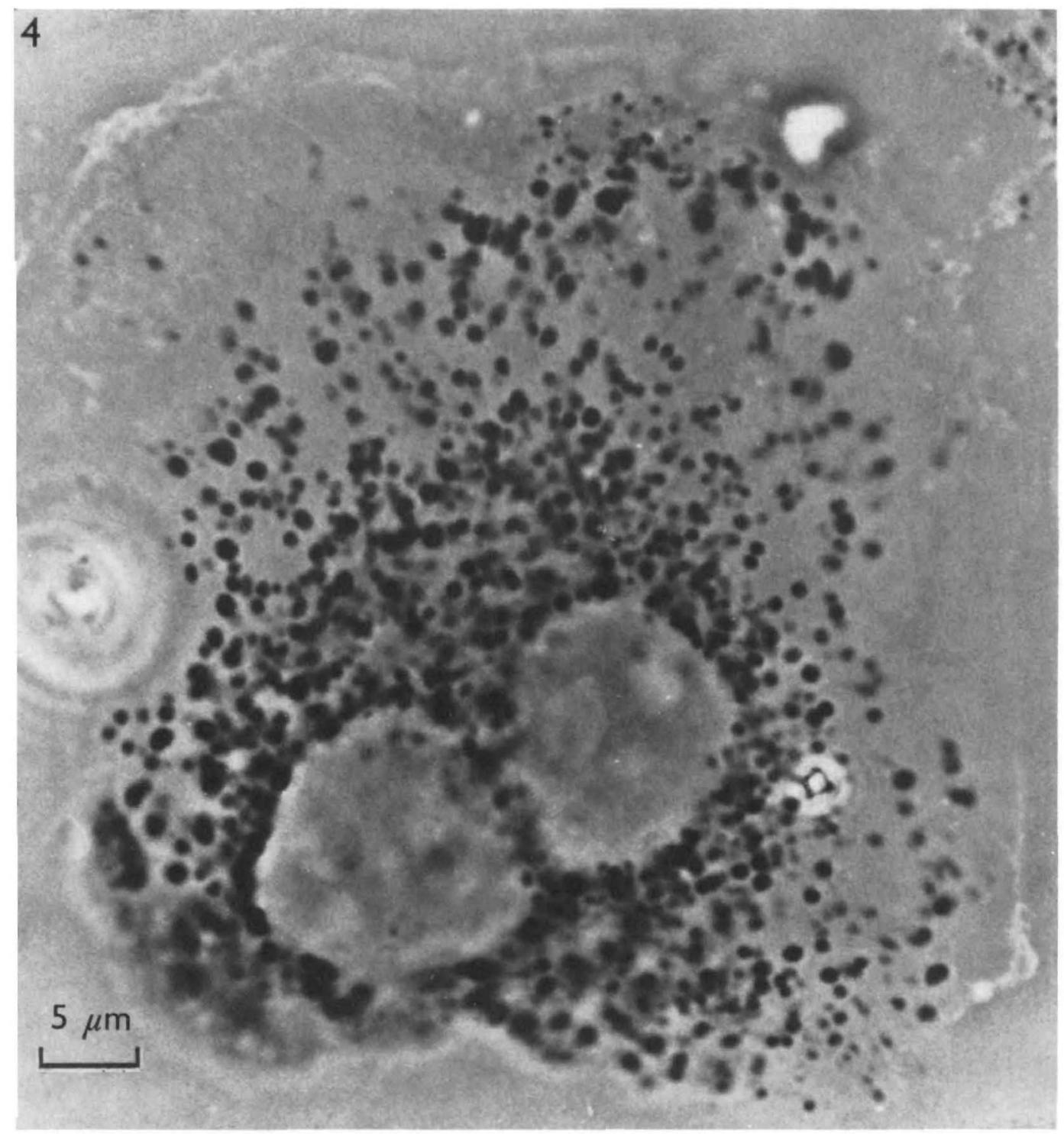

Figs. 4-7. Light micrographs of individual HeLa F-3 5 cells from the same coverslip culture, illustrating the cell-to-cell heterogeneity in mitochondrial morphology, as revealed by the modified DAB staining procedure.

Fig. 4. HeLa F-3 15 cell in which the mitochondria appear as round or oval bodies. Note the apparent discreteness of the organelles in the peripheral portion of the cytoplasm. Oil-immersion phase-contrast, $\times 2500$. 


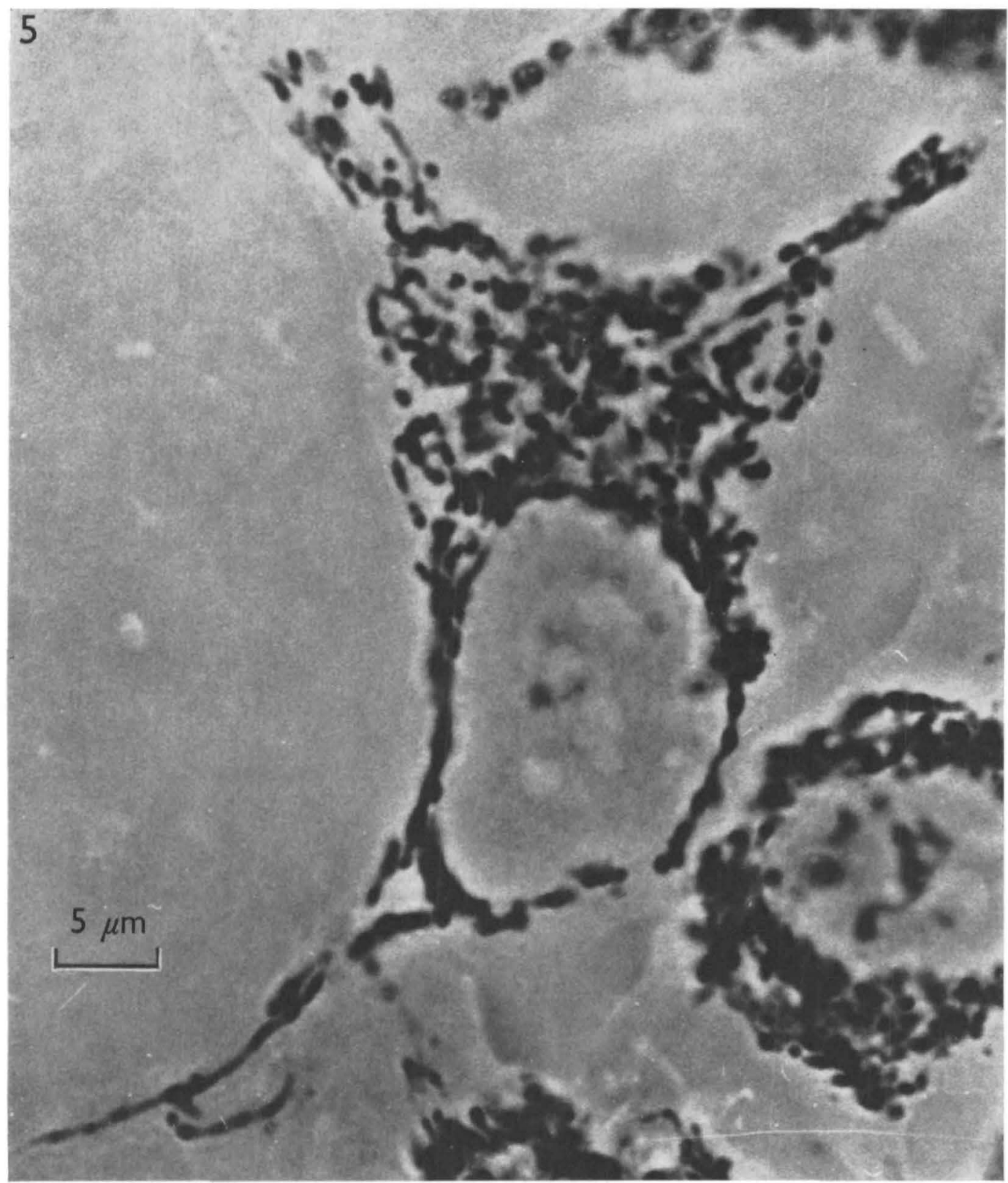

Fig. 5. HeLa F-315 cell showing mitochondria in the shape of short rods, many with an uneven distribution of stain. Oil-immersion phase-contrast, $\times 2900$. 


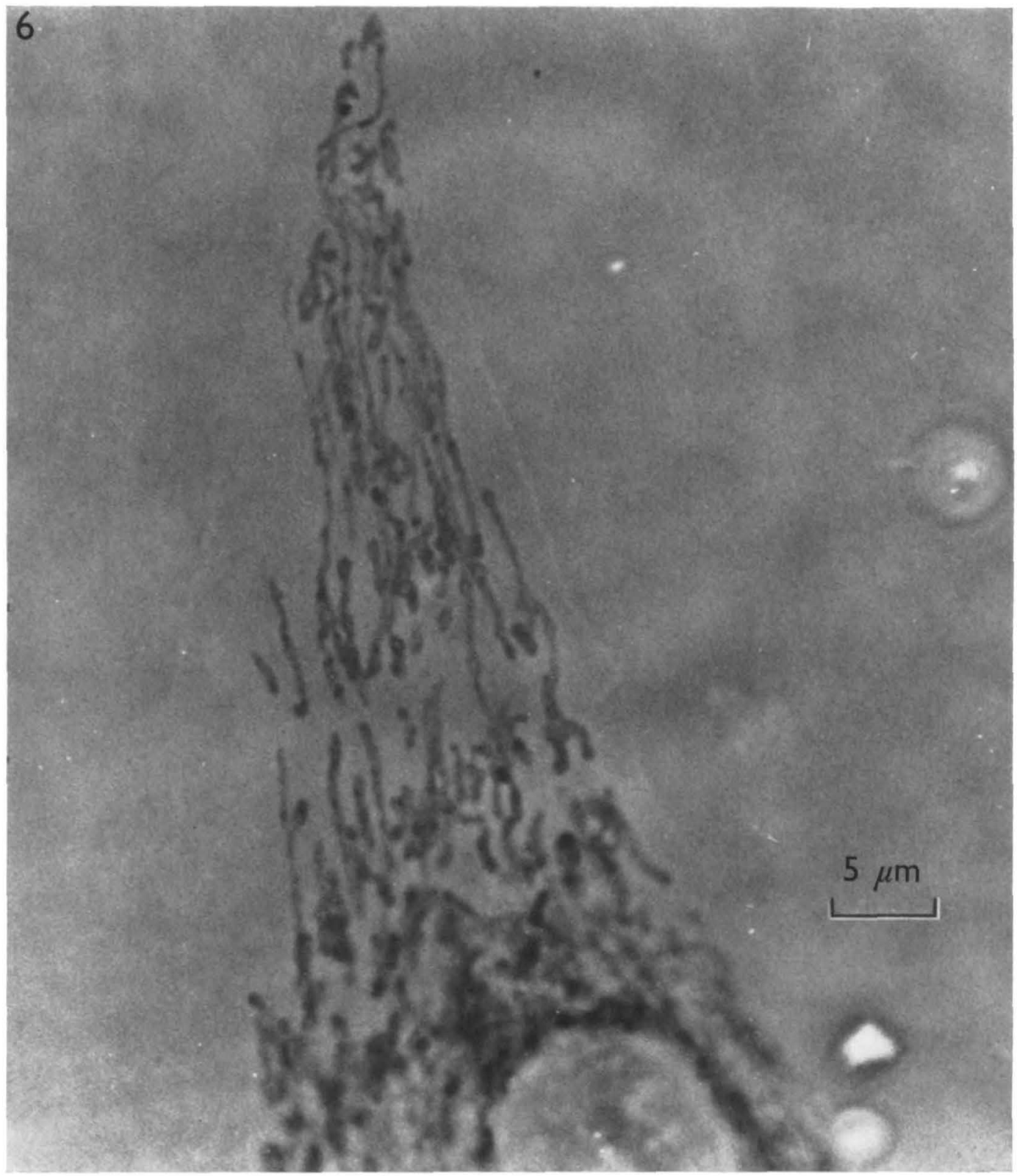

Fig. 6. HeLa F-3 I 5 cell displaying long, thread-like mitochondria. In most cells of this type, the intensity of the stain along the filaments is more uneven than shown here. Note that a few of the organelles appear branched. Oil-immersion phase-contrast, $\times 2700$. 


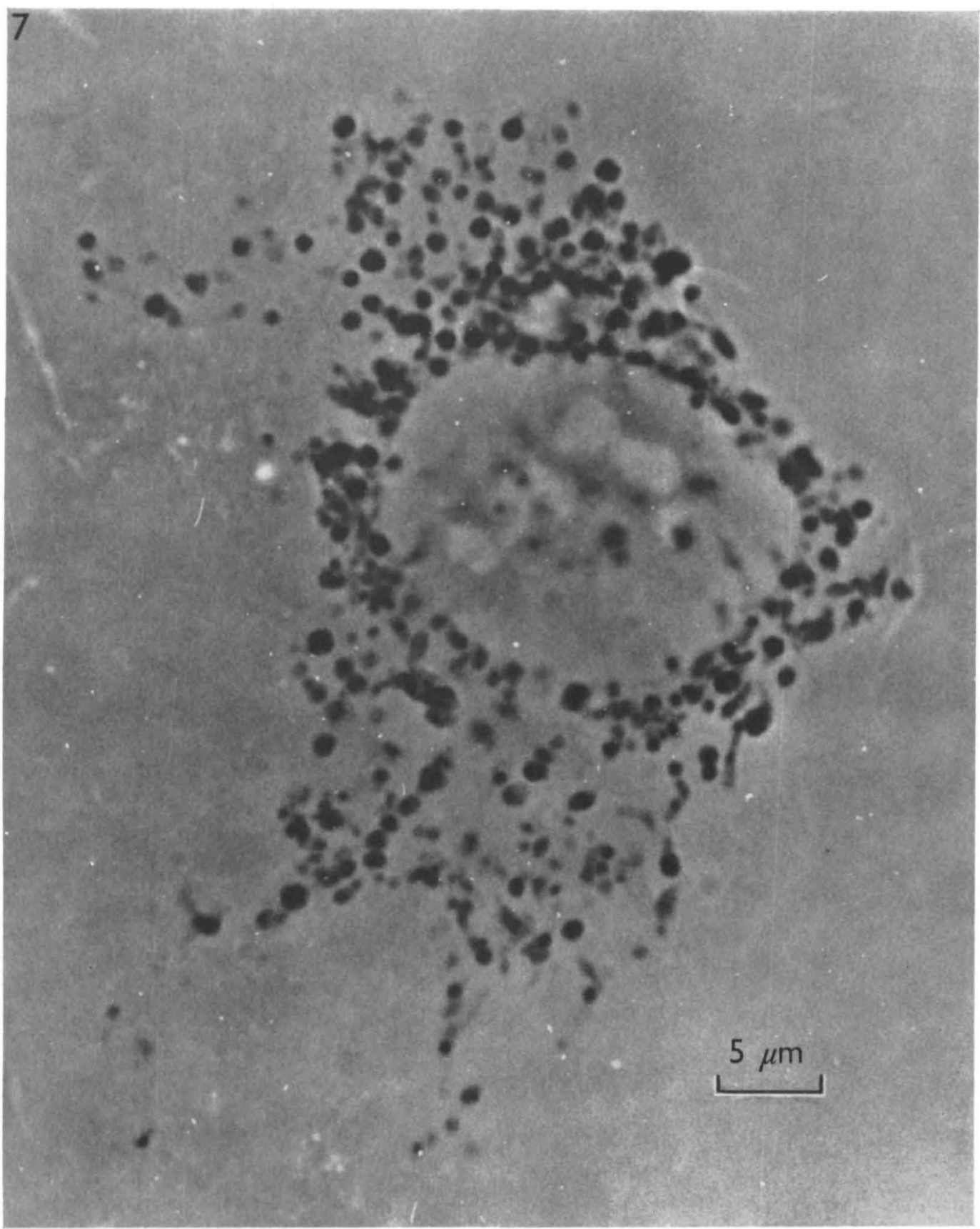

Fig. 7. HeLa F-3 5 cell containing mitochondria of 2 different shapes. Those near the top of the figure are of the round or oval type, while some of those near the bottom are rod-like. Note that the organelles appear as discrete bodies. Oil-immersion phasecontrast, $\times 2900$. 
